\title{
Pre-service primary teachers' argumentation in socioscientific issues
}

\author{
Charlotte Pezaro, Tony Wright, and Robyn Gillies \\ School of Education, The University of Queensland, St Lucia, Australia \\ For correspondence: c.pezaro@uq.edu.au
}

\begin{abstract}
Even in the context of a university science course, students make and attempt to defend unscientific claims in personal and scientific contexts. This research examined a random sample of rhetorical arguments submitted by 130 first-year students in a pre-service primary teaching program for the presence and quality of research evidence and reasoning. Students were strongly encouraged to review the evidence with an open mind before taking a stance. Arguments were analysed by identifying elements of Toulmin's Argument Pattern (Toulmin, 1958) and evaluating the quality of and relationships between these elements using SOLO Taxonomy (Biggs \& Collis, 1982). For the most part, students' claims aligned with scientific consensus; for example, that climate change is almost certainly anthropogenic. However, a small number of students submitted pseudoscientific claims, such as that fluoride should not be added to the water supply. Such claims lack evidence, contradict existing evidence that comes from a strong methodological basis, or rest on weak evidence that comes from a poor methodological basis. Sometimes these claims rely on faulty reasoning or logical fallacies. Concern is not only for those students who have submitted pseudoscientific claims, but also for those students who have presented claims that reflect scientific consensus yet defend those claims with shoddy evidence or poor reasoning. If students cannot distinguish between scientific and pseudoscientific claims, evidence and reasoning, how will they make robust decisions about health, how money should be spent, and how and what they will teach their future students?
\end{abstract}

Keywords: argumentation, science education, Toulmin, SOLO Taxonomy, pre-service teacher education

\section{Introduction}

Pre-service primary teachers require further instruction in the nature of science to improve their construction of arguments regarding socioscientific issues. Thinking as argument is fundamental to decision-making, and as primary teachers are expected to make significant decisions regarding the curriculum, pedagogy, strategies and programs to support student learning, they must become skilled at using science effectively to make decisions that maximise outcomes for their students. Effective scientific argumentation requires a sophisticated understanding of the nature of science, as well as argument structure.

"Thinking as argument is implicated in all of the beliefs people hold, the judgments they make, and the conclusions they come to; it arises every time a significant decision must be made. Hence, argumentive thinking lies at the heart of what we should be concerned about in examining how, and how well, people think" (Kuhn, 1992, p155).

For many people, the most significant way in which higher order thinking and reasoning are used is in argumentation. The process of argumentation reveals the beliefs and opinions people hold about important social and scientific issues (Kuhn, 1992), as well as political, economic, professional and personal issues. Argumentation is central to achieving the goals of science, as scientists critically analyse the ideas of others and make their case for new ideas (Driver, Newton \& Osborne, 2000; Kuhn, 1993; Osborne, 2010). Given the inherent role of argumentation in scientific endeavour for producing reliable knowledge about the natural world, it is surprising that there are not more opportunities for students to practice reasoning and argumentation in the science classroom. 
Scientific literacy and the nature of science. Recent research has identified argumentation as a necessary aspect of any science curriculum that aims to develop students' scientific literacy (McDonald, 2010; McDonald \& McRobbie, 2012; Tytler, 2007). Although difficult to define, scientific literacy is generally taken to mean an understanding of and appreciation for the nature of science (McDonald, 2010). For the purposes of assessing students' scientific literacy by the means of a paper test, the OECD PISA has defined scientific literacy as "the capacity to use scientific knowledge, to identify questions (investigate) and to draw evidence-based conclusions in order to understand and help make decisions about the natural world and the changes made to it through human activity" (1999, p60). Scientific literacy and an understanding of the nature of science are strongly interrelated. The nature of science embodies an epistemological view of science as a way of knowing, and "the values and beliefs inherent to the development of scientific knowledge" (Lederman, 1992, p331). Individual conceptions of the nature of science reflect beliefs about scientific knowledge as moral, tentative, empirical, parsimonious, and a product of human creativity and endeavour (Lederman, 1992). Implicit assumptions that students will develop an understanding of the nature of science from engaging in scientific inquiry without explicit instruction in the nature of science have been found to be unsuccessful (Sandoval, 2005). Rather, it has been proposed that argumentation can support students to develop more informed understandings of the nature of science (McDonald, 2010), and thus an improved level of scientific literacy. Therefore, curriculums designed with the goal of scientific literacy in mind must emphasise that students make use of data and scientific concepts to construct models and explanations about particular phenomena, and that they should engage in the scientific discourse of proposing and arguing about explanations (Berland \& Reiser, 2008; Driver, Newton \& Osborne, 2000; McNeill \& Krajcik, 2008).

Explanation and argumentation. Explanation and argumentation are distinct but complementary: explanations are an artifact of science around which argumentation occurs, and argumentation is the context in which robust explanations are valued (Berland \& Reiser, 2008; Osborne \& Patterson, 2011). Both explanation and argumentation can be products and the processes by which those products are derived (Berland \& Reiser, 2008; Kuhn \& Udell, 2003). However, while research has shown that some teachers are successfully teaching students to develop explanations (McNeill \& Krajcik, 2008), it appears teachers have more difficulty developing student skills and knowledge of argumentation. Driver, Newton and Osborne argue for a science curriculum in which argumentation, as both a process and a product, are central (2000). This curriculum would present science as "a process in which scientific knowledge is socially constructed, and in which discursive activity is central" to this process (p290).

In the classroom, as in the scientific community, the process of argumentation serves to expose and address inconsistencies between ideas and evidence. Individuals engaged in argumentation must make sense of observed phenomena and articulate their understandings, in order to persuade others of their ideas (Berland \& Hammer, 2012). Berland and Reiser (2008) describe three goals for constructing and defending science explanations: sense making, articulating and persuading. The first goal, sense making, is for students to use evidence and scientific concepts to make sense of specific phenomena. The second goal, articulating, requires students to articulate their understandings. Finally, the goal of persuading others can be met when students engage in the social process of considering and reconciling alternative and competing ideas to construct a robust explanation of a phenomenon. This final goal shifts the classroom emphasis from "doing school," in which the ultimate goal is to please the teacher by finding a correct answer, to "doing science", in which finding a consensus is the ultimate goal.

Formats for argumentation. Outside of school classrooms, argumentation is a human practice undertaken in specific social contexts. Two forms of argumentation can be described: the didactic and the dialogic. Didactic (also known as rhetorical) argument, prevalent as a product of classroom activities and the most researched form of argumentation (Kuhn \& Udell, 2003), is often used to inform others of a claim and persuade them of its reasonableness. This form of argument is often onesided, and can rely on authority rather than evidence and explanation (Jimenez-Aleixandre, Rodriguez \& Duschl, 2000). Russell (1983) analysed teacher-led classroom discourse and found that often teachers draw on their authority for support, consequently omitting or reducing the evidence 
and explanation required to support their claims. This epistemological position also reduces student participation in dialogic argumentation (Berland \& Hammer, 2012). Didactic arguments are often presented as final products, with little examination of the process of argumentation itself.

Dialogic argumentation is a process of examining multiple perspectives, with the purpose of reaching agreement on acceptable claims or course of action. These arguments can take place individually or as a social group. Framing a context in which argumentation is called for is vital (Berland \& Hammer, 2012). Many of the skills and principles required to participate effectively in dialogic argumentation are analogous to those required to make reliable decisions in socioscientific contexts. Evaluating alternatives is a key skill in making useful decisions. Participating in dialogic argumentation requires students to evaluate alternative positions (Driver, Newton \& Osborne, 2000). Meeting this goal requires students to construct and revise their own and others' claims, evidence and reasoning (Berland \& Hammer, 2012). Dialogic argumentation requires students to make sense of phenomena, articulate their understandings, and persuade others to commit to their position. Habits of mind developed by dialogic argumentation include adopting a critical stance, willingness to ask questions and seek help, developing a sense of appropriate trust, and finally, scientific scepticism (Duschl, Schweingruber \& Shouse, 2007). However, it has been noted that the same skills entailed in dialogic argumentation are implicit in didactic argumentation, as it is the framing of an argument in opposition to another assertion that makes the argument necessary in the first place (Kuhn, 1992).

Argument structure. Both dialogic and didactic arguments contain a common set of typical elements. In the science education research literature (for examples see: Driver, Newton \& Osborne, 2000; Simon, 2008; Erduran, Osborne \& Simon, 2004; Berland \& Reiser, 2008), a commonly used set of transdisciplinary argument patterns is based on the definitions given by Stephen Toulmin in his book The Uses of Argument (2003). The fundamental elements of an argument are described: claims, data (facts, evidence), warrants (premises), backing (explanation, reasoning), counterarguments (refutations). A sixth element, qualifiers, describes the use of modal terms and statements. Claims, warrants and data are considered essential to an argument, while backing, rebuttals and qualifiers may not always be needed. Arguments can also be hierarchical, in that the backing for one claim can be considered a new claim requiring its own data and warrants, etc.

Argument coherence. The main body of research into scientific argumentation has focused on the components and contexts of argumentation (Driver, Newton \& Osborne, 2000; Berland \& Hammer, 2012). The evaluation of a didactic argument's coherence, consistency, and strength of support for the claim by warrants, data and backing has little been discussed in the literature. However, proposals for assessment models that can be applied in multiple or general contexts are many, for example Bloom's Taxonomy (Bloom, 1956). The Structure of the Observed Learning Outcome (SOLO) Taxonomy, proposed by Biggs and Collis in 1982, describes qualitative assessment by evaluating the structure as fitting into one of five levels of increasing complexity: Prestructural, in which there is no relevance or coherence between elements; Unistructural, in which a single relevant idea is focused upon; Multistructural, in which multiple ideas are generalised in a conclusion, additively; Relational, in which multiple related ideas lead to a credible and supported conclusion; and Extended Abstract, in which multiple related ideas are extended to resolve inconsistencies, and conclusions are held open or qualified to allow logically possible alternatives (Biggs \& Collis, 1982).

Explicit instruction in argumentation. Initial studies in argumentation demonstrated that higher levels of argumentation were rarely seen in adults and children. These findings (see Kuhn et al 2000, for example) resulted in a deficit view of individuals' reasoning abilities, inspiring instruction that presented argumentation as a set of skills that could be developed through explicit instruction and scaffolding regarding the strategies of argumentation. Researchers undertaking design studies, such as those by Simon, Erduran and Osborne (2006), Sampson, Grooms and Walker (2011) and Chin and Osborne (2010) have produced evidence that gains in argumentation skills were a result of explicit instruction. However, a growing body of evidence is demonstrating that students are more skilled arguers than expected, when the context calls for it (Berland \& Hammer, 2012). Such a context is framed socially, through individuals' dynamic vocal tones, word choices and body language. This context avoids traditional epistemology, where the teacher or a textbook are authoritative and not to 
be questioned, seeking instead a rational epistemology, where authority is given to evidence and reasoning (Berland \& Hammer, 2012; Berland \& Reiser, 2008; Driver, Newton \& Osborne, 2000). Students in this learning environment hold a sense of what they are trying to accomplish and understand that the purpose of discussion aligns with that of scientific argumentation. Rather than "doing the lesson", students are "doing science" (Jimenez-Aleixandre, Rodriguez \& Duschl, 2000). Students "doing the lesson" are engaged in a teacher-controlled activity that produces pseudoargumentation with the goal of satisfying the teacher. Students "doing science" hold a large degree of control over the activity, and accept ideas only if they make sense and fit with the available evidence. Furthermore, research has shown that extended exercise in thinking and reasoning skills in a cognitively rich environment serves as a sufficient condition for the development of argumentation skills (Kuhn \& Udell, 2003). Unfortunately, this context for argumentation is vastly different from that in schools today, and changing the context for students is difficult as they have a set schema of expectations for science lessons that may be difficult to overrule.

\section{Aim}

This study explores the quality of arguments written by first-year education students. Written rhetorical arguments submitted for assessment in a foundational science course were examined for coherence and consistency using the SOLO Taxonomy. The quality of claims, data, and sources of data used were evaluated. The use of logical fallacies and other faulty reasoning was identified. The findings of this study contribute to a larger project investigating the relationship between learning science, scientific argumentation, and decision-making.

\section{Method}

Participants. Research participants were randomly selected from a population of 136 students enrolled in a first year university course in fundamental science concepts, Introduction to the Role of Science and Technology Education. This course forms part of the Bachelor of Education (Primary) program at a large metropolitan university in Queensland. These students are mostly first year students, in their late teens and recently graduated from high school. Some have taken a gap year or are mature-aged students returning to university to prepare for a new career. This population is primarily Australian, and largely from Queensland. There are a few international students, largely from China and Korea. The entry scores required for enrolment in the Bachelor of Education (Primary) program are slightly above average or better in high school achievement. All students were given advice and support for preparing their arguments in tutorial activities that focused on the structure, components and appropriate sources of data.

Context. Rhetorical arguments were submitted as summative assessment pieces by students enrolled in the course Introduction to the Role of Science and Technology Education. The course is an introduction to science for pre-service primary and middle years' teachers. Assessment included the written argument, written artefacts relating to an experimental investigation or inquiry, and a series of 10 weekly quizzes that aimed to assess conceptual knowledge. Course content was derived from the Australian Curriculum: Science from Foundation to Year 10 (ACARA, 2013). The Australian Curriculum: Science was recently developed and reflects the scientific knowledge, skills and understandings valued by the broader community. It is similar to past Queensland curricula and syllabi (QSA, 2007), with a large overlap of content. It is also similar in both purpose and content to other curricula around the world, including the United Kingdom National Curriculum in Science (DEEQCA, 2004) and the United States of America Next Generation Science Standards (NSTA, 2012).

To complete their written arguments, students were required to research a socioscientific issue of interest, identify all stances on the issue, and decide which had the most evidence and best scientific explanation. Students were strongly encouraged to suspend their own opinions and to review the literature with an open-mind before deciding on a stance. From this research, students wrote a structured argument defending their identified stance with evidence and explanation, rebutting counterarguments with evidence and reasoning where possible. Arguments were to be less than 1000 words and submitted through the system Turnitin, which identifies plagiarism from online sources. 
Due to the limitations of the assessment, students were discouraged from presenting ethical arguments, although the importance of ethical discussion in science was highlighted. Scaffolding was provided during tutorial contact with students as well as resources provided through the online classroom system Blackboard. This assessment was completed individually, and weighted as 30 per cent of the course grade.

Prior to final submission of their written arguments, students anonymously gave and received feedback to and from their peers using the Turnitin Peer Review system. Peer review of argument drafts was scaffolded by four questions that required responses, and students also provided in-text comments regarding argument structure, referencing, reasoning and scientific content. The questions were as follows:

1. Does this paper sustain a coherent point of view? Why or why not?

2. Can the conclusion of this paper be convincingly drawn from the thesis and the argument made in the body of the paper? Why or why not?

3. Do you feel this paper relies on evidence, or on opinion or intuition? If the latter, cite examples of where this paper relies on opinion and intuition and give suggestions as to how the writer can write more objectively.

4. How smoothly does this paper integrate examples into its own argument? Does it clearly illustrate connections between the evidence it cites and the ideas they support, or does it merely assume them?

Procedure. Altogether, 130 written arguments were submitted by students to the course coordinator in the 2013 iteration of the course. From this pool, twenty-six written arguments were randomly selected using a random selection formula in Excel. Table 3 in the Results section of this paper describes the twenty-six sample arguments, including the argument topic, conclusion and a grade assigned by a skilled and experienced course tutor according the university's expected 1-7 grade scale, with 7 the highest grade possible and 1 the lowest. The average grade of the twenty-six arguments was 5.38; this is very similar to the average grade of all arguments, which was 5.39 .

Data analysis. These arguments were then analysed for quality in a number of areas. Each argument was deconstructed so that claims, warrants, data, backing, qualifiers, counterarguments and rebuttals were identified in line with Toulmin's Argument Pattern (Toulmin, 2003). The six elements of an argument are outlined in Table 1 alongside an example argument. It is interesting to note that this model prioritises evidence (data) over explanation (backing), as seen in Figure 1.

Counterarguments may not describe conditions or circumstances of exception, but may be direct arguments in themselves that present reasoning or evidence counter to the claims of the main argument. The inclusion of counterarguments in a rhetorical argument demonstrates that the author is able to consider other points of view. Rebuttals are warrants that debunk, dismiss or defuse the counterarguments. The main argument can best be preserved by the presentation of data or backing that rebuts the counterarguments. In the argument example provided above in Table 1: Six elements of an argument, the counterargument that the measles vaccine may have side effects is rebutted by the warrant that the benefits of immunisation far outweigh the risks. A better quality rebuttal would also list the data and reasoning to support this warrant. A further counterargument is presented about a specific risk (that the MMR vaccine causes autism) by the warrant that this has been debunked and dismissed by scientists. Once again, this rebuttal could be strengthened by data and backing.

Next, the quality of each of these elements was described. Claims were assessed for clarity, implied or explicit qualifiers, and the relationship with a problem statement. Data was classified as qualitative or statistical, and as relevant or irrelevant to the claim. The sources of data were counted and classified as primary, secondary or tertiary, and credible or not credible (i.e. information sheets supplied from MS Australia were deemed as generally credible, while information sheets sourced from Natural News not so). Warrants were categorized as explicit or implicit, or if they involved tautology or transduction, induction or deduction. The quality of backing or explanatory statements was evaluated for relevance, credibility, accuracy and sufficiency. Logical fallacies were identified in both warrants 
and backing statements, if present. Student understanding of scientific concepts was demonstrated by the clarity, coherence and relevance of the backing. Counterarguments were either absent, explicit, or implicit in the rebuttal of counterarguments. They could also be either relevant or irrelevant, and supported by data or backing. Rebuttals (a form of warrant), if present, could also be classed as either relevant or irrelevant (missing the point), and supported by data or backing.

Table 1. Six elements of an argument (Toulmin, 2003).

\begin{tabular}{|c|c|c|}
\hline Element & Description & Example \\
\hline Claim & $\begin{array}{l}\text { Position, stance on an issue; the } \\
\text { central idea }\end{array}$ & $\begin{array}{l}\text { Vaccinations are effective at reducing the spread of } \\
\text { dangerous diseases, such as measles. }\end{array}$ \\
\hline Data & $\begin{array}{l}\text { Evidence, facts, information; } \\
\text { evidence should be sufficient, } \\
\text { credible, accurate }\end{array}$ & $\begin{array}{l}\text { Reported cases of measles in the United States fell } \\
\text { from hundreds of thousands prior to the introduction } \\
\text { of the vaccine to just under } 200 \text { each year since } 1997 \text {. }\end{array}$ \\
\hline Warrant & $\begin{array}{l}\text { Reasons, assumptions, beliefs, } \\
\text { values, principles; link between } \\
\text { the claim and the evidence; can } \\
\text { be implicit or explicit }\end{array}$ & $\begin{array}{l}\text { Measles is a dangerous disease that can lead to } \\
\text { complications or fatality. } \\
\text { Dangerous diseases such as measles should be } \\
\text { prevented from spreading. }\end{array}$ \\
\hline Backing & $\begin{array}{l}\text { Explanations, theoretical } \\
\text { assumptions; the scientific } \\
\text { backing for warrants }\end{array}$ & $\begin{array}{l}\text { The vaccine against measles works by priming the } \\
\text { immune response of the body. The immune system } \\
\text { develops antimeasles immuno-globulins in response } \\
\text { to exposure to a small amount of the live attenuated } \\
\text { virus. }\end{array}$ \\
\hline $\begin{array}{l}\text { Counter- } \\
\text { argument }\end{array}$ & Conditions of exception & $\begin{array}{l}\text { The measles vaccine may cause adverse reactions, } \\
\text { though these are rarely serious, and the benefits of } \\
\text { immunisation far outweigh the risks. Claims that the } \\
\text { MMR vaccine causes autism have been strongly } \\
\text { debunked and dismissed by scientists. }\end{array}$ \\
\hline Qualifier & $\begin{array}{l}\text { Modal terms used for } \\
\text { expressing the degree of } \\
\text { certainty or relative strength of a } \\
\text { claim }\end{array}$ & $\begin{array}{l}\text { There is a set of people who cannot safely receive } \\
\text { vaccines, for example those who are } \\
\text { immunocompromised or who have been confirmed as } \\
\text { sensitive or allergic to the ingredients of the vaccine. } \\
\text { The use of the terms 'may', 'rarely' and 'strongly' in } \\
\text { the statement above informs us that the measles } \\
\text { vaccine does not always cause adverse reactions, that } \\
\text { adverse reactions are rare, and that the evidence } \\
\text { against the claim is strong. }\end{array}$ \\
\hline
\end{tabular}

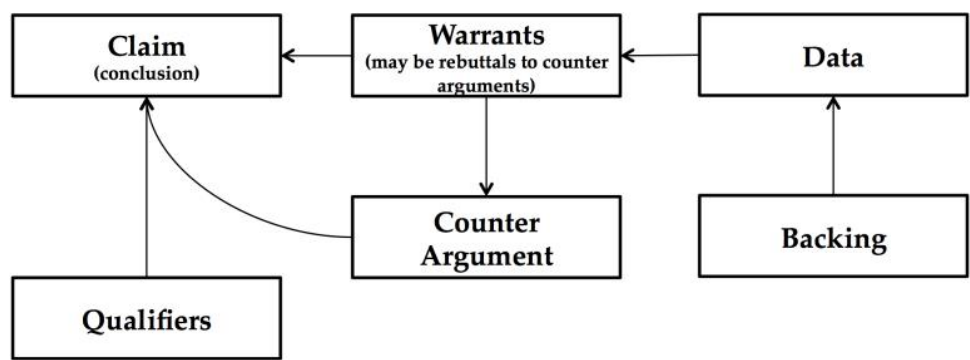

Figure 1. Toulmin's argument pattern, adapted by the author.

All elements were evaluated in the context of the entire argument, and the overall quality of the argument assigned to a SOLO level according to the coherence, relating operations, consistency and closure, and overall structure of the argument as described in Table 2 (Biggs \& Collis, 1982). 
Table 2. Using the SOLO Taxonomy to evaluate rhetorical arguments.

\begin{tabular}{|c|c|c|}
\hline SOLO level & $\begin{array}{l}\text { General features (Biggs \& Collis, } \\
\text { 1982) }\end{array}$ & $\begin{array}{l}\text { Features of a rhetorical argument at this } \\
\text { level }\end{array}$ \\
\hline Prestructural & $\begin{array}{l}\text { Cue and response confused } \\
\text { No understanding } \\
\text { Inconsistent, contradictory } \\
\text { Mismatch between cue and response } \\
\text { Denial, tautology, transduction }\end{array}$ & $\begin{array}{l}\text { No match between claim and data or claim } \\
\text { and warrants } \\
\text { Claim and data or claim and warrants } \\
\text { inconsistent or contradictory }\end{array}$ \\
\hline Unistructural & $\begin{array}{l}\text { Focus on one relevant aspect } \\
\text { Conclusion quickly reached } \\
\text { Limited generalisability }\end{array}$ & $\begin{array}{l}\text { Claim and one relevant warrant } \\
\text { Conclusion not wholly supported by data } \\
\text { Repetition of warrants, data }\end{array}$ \\
\hline Multistructural & $\begin{array}{l}\text { Focus on several independent but } \\
\text { relevant aspects, separately and } \\
\text { additively } \\
\text { Limited generalisability }\end{array}$ & $\begin{array}{l}\text { Claim and isolated relevant warrants or } \\
\text { data } \\
\text { May come to one of several possible } \\
\text { conclusions from warrants and data } \\
\text { presented }\end{array}$ \\
\hline Relational & $\begin{array}{l}\text { Several relevant aspects integrated } \\
\text { into a coherent whole } \\
\text { Links or relationships are made } \\
\text { Consistency within given context } \\
\text { Comparison, induction }\end{array}$ & $\begin{array}{l}\text { Claim, data and warrants are interconnected } \\
\text { Conclusion adequately reasoned from all } \\
\text { warrants and data presented } \\
\text { Counterargument, if present, not adequately } \\
\text { rebutted }\end{array}$ \\
\hline $\begin{array}{l}\text { Extended } \\
\text { Abstract }\end{array}$ & $\begin{array}{l}\text { Integrated whole conceptualised at } \\
\text { highest level and generalised to new } \\
\text { topic or area } \\
\text { Generalisation, hypothesis, } \\
\text { theorising } \\
\text { Inconsistencies resolved } \\
\text { Open conclusions, or qualified to } \\
\text { allow logically possible alternatives } \\
\text { Deduction and induction, broad } \\
\text { generalisation }\end{array}$ & $\begin{array}{l}\text { Claim, data and warrants are interconnected } \\
\text { and extended } \\
\text { Qualifiers describe conditions when the } \\
\text { given claim does not hold true } \\
\text { Modifiers indicate level of certainty in claim, } \\
\text { warrants, or data } \\
\text { Conclusion/s wholly supported by data, } \\
\text { qualified to allow logically possible } \\
\text { alternatives } \\
\text { Gaps in either personal or research } \\
\text { knowledge acknowledged } \\
\text { Inconsistencies or counterarguments } \\
\text { addressed }\end{array}$ \\
\hline
\end{tabular}

This analysis not only allows for an overall determination of the quality of participants' rhetorical arguments, but also for identification of participants' general strength and weaknesses in the construction of an argument.

\section{Results}

Structure of the Observed Learning Outcome. In the twenty-six arguments, the full gamut of SOLO levels was identified. Table 3 lists the sample set of arguments, their topic, claim and the identified SOLO level. Only four arguments were identified as meeting the criteria for the advanced Relational or Extended Abstract levels of the SOLO Taxonomy. These arguments integrated several relevant warrants into a coherent whole in which relationships are established and comparisons made between alternatives, leading to a reasonable conclusion (claim) supported by data and backing. Qualifiers described conditions in which the claim or warrants may not be valid; constructive discussions of the methodologies of supporting studies were provided. The conclusion of the argument identified as having features of the Extended Abstract level of the SOLO Taxonomy was wholly supported by the data, with counterarguments addressed, gaps in the research or explanations identified, and logical alternatives discussed.

Claims in support of the scientific consensus position. For the most part, claims aligned with the consensus described in current scientific literature, and were presented with at least one relevant and reasonable 
warrant, backing and/or data, usually derived from a number and variety of sources. However, despite the recognition of a scientifically valid claim, the coherence and consistency of the arguments to support such claims was highly variable, with half of all arguments classified as demonstrating basic levels of coherence and consistency according to the SOLO Taxonomy.

Claims that contradicted the scientific consensus position. Of the sample 26 arguments explored, only one argument did not align with the scientific consensus (indicated by an asterisk in Table 3). This particular essay argued against water fluoridation. Features of the Unistructural level of the SOLO Taxonomy were identified. Only one warrant was presented: that fluoride is toxic leading to significant health problems including cancer. This warrant was presented twice. Sources of evidence included three online information sheets, three anti-fluoride campaign websites, one toxicology report, two news articles, one legal finding and one online petition. Of these sources, only the three online information sheets and the toxicology report were deemed to be credible; two of these information sheets were used to support contextual description, rather than any part of the actual argument. A cautious statement made in the third information sheet about a possible hypothesis for the causation of cancer by fluoride was presented as factual. Regarding the toxicology report, data that contradicted the author's claim was excluded, and their findings misrepresented; a logical fallacy known as cherry picking. No discussion of toxicity was given. An appeal to the authority of a university professor was used to support claims. The conclusion was not wholly supported by the data.

Data. Analysis of the data types used and their relevant to the argument indicated that participants do not discriminate between the quality and types of data that can be used to support claims. Three arguments were presented that did not contain any data to support warrants or the claim. In other arguments, data presented was not credible, accurate, or sufficient. Qualitative statements describing the findings of studies were presented to support the claim or warrant. Links were not always made between data and warrants or data and backing. In a few arguments, relevant statistics were provided from empirical sources that demonstrated support for the warrants or claim. Occasionally, data were also provided to demonstrate a difference with control or other treatment groups, demonstrating methodological awareness of the author. Only six arguments were deemed to have presented data that was credible, accurate and sufficient.

Sources of data. While most arguments included citations of peer-reviewed journal articles in support of claims, warrants, data and backing, a variety of other sources were also used, including information sheets provided online by various agencies, some with a strong positive reputation for credible information, e.g. the World Health Organisation, others known to provide inaccurate or misrepresented data to forward a political or social agenda, e.g. Fluoride Australia. Books were heavily relied upon as sources of information, along with online blog posts and magazine and news articles. Wikipedia was occasionally cited, along with similar online or print encyclopaedias. Interestingly, several magazines for children were cited as sources of information.

Counterarguments and rebuttals. Counterarguments were presented in all but two arguments. Six arguments forwarded counterarguments without rebuttal. A further three rebuttals were irrelevant. Nine rebuttals were relevant but inadequate.

Qualifiers. Four arguments included clear, explicit, well-defined qualifiers and another nine arguments included superficial, implicit or obvious qualifiers. The remaining thirteen arguments did not contain any statements of qualification. 
Table 3. List of twenty-six sample arguments identified by SOLO level.

\begin{tabular}{|c|c|c|}
\hline Topic & Claim & Grade \\
\hline Cloning & $\begin{array}{l}\text { Cloning could be a solution to humanity's greatest } \\
\text { problems }\end{array}$ & Prestructural \\
\hline $\begin{array}{l}\text { Dredging of the Great } \\
\text { Barrier Reef }\end{array}$ & Dredging should be discontinued & $\begin{array}{l}\text { Prestructural transition } \\
\text { to Unistructural }\end{array}$ \\
\hline $\begin{array}{l}\text { Earphones and hearing } \\
\text { impairment }\end{array}$ & $\begin{array}{l}\text { Listening to music through earphones can cause hearing } \\
\text { impairment }\end{array}$ & Unistructural \\
\hline Water fluoridation & $\begin{array}{l}\text { Water fluoridation is an effective and important public } \\
\text { health policy }\end{array}$ & Unistructural \\
\hline Water consumption & Humans do not need to drink 8 glasses of water each day & Unistructural \\
\hline Anabolic steroids in sport & Use of steroids is detrimental in the long-term & Unistructural \\
\hline Male contraception & Male contraception is superior to female contraception & Unistructural \\
\hline Older parents & $\begin{array}{l}\text { There are more risks for children born to parents over the } \\
\text { age of } 40\end{array}$ & Unistructural \\
\hline Water fluoridation* & Fluoride should not be added to the water & Unistructural \\
\hline Climate change & $\begin{array}{l}\text { Climate change is a result of increased industrial } \\
\text { production }\end{array}$ & $\begin{array}{l}\text { Unistructural } \\
\text { transition to } \\
\text { Multistructural }\end{array}$ \\
\hline $\begin{array}{l}\text { Performance enhancing } \\
\text { drugs (PED) }\end{array}$ & $\begin{array}{l}\text { Drug use in sports is dangerously detrimental to physical } \\
\text { and mental health in athletes }\end{array}$ & $\begin{array}{l}\text { Unistructural } \\
\text { transition to } \\
\text { Multistructural }\end{array}$ \\
\hline $\begin{array}{l}\text { Caffeinated energy drinks } \\
\text { (CED) }\end{array}$ & CED cause harm to the human body & $\begin{array}{l}\text { Unistructural } \\
\text { transition to } \\
\text { Multistructural }\end{array}$ \\
\hline Animal testing & $\begin{array}{l}\text { Animal testing is currently a necessary aspect of } \\
\text { pharmaceutical development }\end{array}$ & $\begin{array}{l}\text { Unistructural } \\
\text { transition to } \\
\text { Multistructural }\end{array}$ \\
\hline $\begin{array}{l}\text { The medicinal value of } \\
\text { cannabis }\end{array}$ & $\begin{array}{l}\text { There is value in prescribing cannabis for the treatment } \\
\text { of various medical issues }\end{array}$ & Multistructural \\
\hline Diet & $\begin{array}{l}\text { The calorie-in, calorie-out approach to weight loss is the } \\
\text { most sound and empirically supported }\end{array}$ & Multistructural \\
\hline Antibiotics & $\begin{array}{l}\text { Antibiotic resistance is a problem that doctors, patients } \\
\text { and pharmaceutical companies must respond to }\end{array}$ & Multistructural \\
\hline Coffee & $\begin{array}{l}\text { Drinking coffee in moderation is not bad for you and } \\
\text { may be advantageous }\end{array}$ & Multistructural \\
\hline Energy drinks & $\begin{array}{l}\text { Children under } 13 \text { yo should not be allowed to consume } \\
\text { energy drinks }\end{array}$ & Multistructural \\
\hline Vaccination & $\begin{array}{l}\text { Vaccination should be compulsory for enrolment in } \\
\text { public schools in Queensland }\end{array}$ & Multistructural \\
\hline Ketamine & $\begin{array}{l}\text { Ketamine should be used in the treatment of major } \\
\text { depressive disorders }\end{array}$ & Multistructural \\
\hline Animal testing & $\begin{array}{l}\text { Animal testing should not be used in the development of } \\
\text { pharmaceuticals }\end{array}$ & $\begin{array}{l}\text { Multistructural } \\
\text { transition to } \\
\text { Relational }\end{array}$ \\
\hline $\begin{array}{l}\text { Laparoscopic adjustable } \\
\text { gastric banding (LAGB) }\end{array}$ & $\begin{array}{l}\text { LAGB is an effective way to improve the health and } \\
\text { quality of life of the morbidly obese }\end{array}$ & $\begin{array}{l}\text { Multistructural } \\
\text { transition to } \\
\text { Relational }\end{array}$ \\
\hline Animal testing & $\begin{array}{l}\text { Animal testing is currently necessary to advance medical } \\
\text { research }\end{array}$ & Relational \\
\hline Vaccination & $\begin{array}{l}\text { Vaccinations are an effective means of protecting society } \\
\text { from infectious disease }\end{array}$ & Relational \\
\hline Artificial reefs & $\begin{array}{l}\text { Sustainable artificial reefs can slow the decline of the } \\
\text { world's marine population }\end{array}$ & Relational \\
\hline Gastric bypass surgery & $\begin{array}{l}\text { Gastric bypass surgery is the most effective treatment for } \\
\text { diabetes type } 2\end{array}$ & Extended Abstract \\
\hline
\end{tabular}


Logical fallacies. Logical fallacies were identified in just over than half of the arguments. Most commonly used fallacies included the appeal to authority, in which a claim or warrant forwarded on the strength of the authority or reputation of a scientist or science organisation. The bandwagon fallacy was second-most commonly presented, in which the argument is made that a claim or warrant must be valid as it is popular. Additional fallacies used included:

- cherry picking, in which data that contradicts the argument is deliberately excluded;

- the naturalistic fallacy in which something is presumed to be good because it is "natural";

- the appeal to emotion, in which an attempt is made to manipulate an emotional response in place of a valid argument;

- special pleading, in which the criteria applied to one warrant are not applied to another; and

- burden of proof, in which a claim is argued as true until someone can demonstrate otherwise. The anecdotal fallacy, in which personal experience or an isolated example is used in the place of statistical data in an argument, was notable by its absence from the sample set of arguments.

\section{Discussion}

Students' rhetorical arguments reveal their views of the world, and also their understandings of the nature of science, scientific methodologies, scientific knowledge, and ability to interpret scientific and non-scientific texts. Importantly, the elemental structure and coherence of the arguments were often unsophisticated, regardless of whether claims aligned with the scientific consensus or did not. The majority of arguments that aligned with the consensus were no more coherent, consistent, better supported with data, explained sufficiently or qualified than the claim of the single argument that contradicted the scientific consensus. The structure of arguments, including identification of various elements and the coherence and consistency of the content, are insufficient for making judgments about their correctness (Driver, Newton \& Osborne, 2000).

Instruction regarding the structure of argument was insufficient to prepare students to make compelling scientific arguments. Assumptions that students had developed an understanding of the nature of science in the compulsory years of schooling were incorrect. In general, evidence provided was irrelevant, insufficient, and in a few cases, inaccurate. Few comments on methodological validity or reliability were made. Students' selection of data sources indicates that they still have a ways to go in learning to distinguish - or perhaps to interpret - credible empirical sources of data. The general lack of statements of qualification may indicate participants' perceptions of science as amoral, definite, and complex. While the majority of arguments included at least one counter argument to their claim, this was one of the requirements of the assessment, and few of the participants were able to adequately rebut them. The inclusion of logical fallacies or flawed reasoning in the majority of arguments may indicate a lack of reasoning skill; this has been identified as an issue for teachers in previous studies (Zohar, 2007).

The analysis of the quality of the elements and coherence of the arguments required more than the objective application of Toulmin's Argument Pattern (Toulmin, 2003) or the SOLO Taxonomy (Biggs \& Collis, 1982). Deep analysis of the arguments required an awareness of scientific (and nonscientific) positions on a broad range of socioscientific issues, an acquired understanding of what constitutes scientific evidence (and what does not), a developed knowledge of a wide range of warrants (implicit and explicit) that support the varied positions of the community, a comprehensive understanding of scientific ideas and concepts, and an appreciation for the tentative nature of science. The construction of a convincing scientific argument requires this same set of skills.

The peer review process, including a response to four focus questions, assisted students to improve their arguments in two ways. First, participants received feedback from their peers about the coherence of their argument, the support for the conclusion, the use of data and objectivity, and the consistency and connections between data and warrants. Second, participants used the process of reviewing others' arguments to reflect on these aspects of their own arguments. This approach needs further investigation to identify any impacts on the quality of student arguments. 
Pre-service primary teachers require skills and understandings to critically examine socioscientific claims if they are to model them in the classroom. A sophisticated understanding of the nature of science and scientific ideas are also required for the effective teaching of and about science to their future students (Zohar, 2007). Without such understanding, the risk is that pre-service primary teachers become teachers who continue to frame science as a subject in which there are clear, unambiguous "correct" answers and data lead uncontroversially to constructed conclusions. It is not a great surprise that this positivist view is held by many teachers themselves, suggesting that the remediation of this problem lies in part with teachers and their beliefs and values (Driver, Newton and Osborne, 2000; Osborne, 2007). Further, pre-service primary teachers require these skills not only for application in everyday contexts and for personal purposes but to evaluate teaching programs, pedagogical research and science curriculums.

\section{Conclusion}

Argument structure and coherence are important for students to express their ideas, but not sufficient for helping students to navigate the overwhelming number of scientific and non-scientific claims put to them in everyday contexts. A pedagogical approach that emphasises the development of understandings of the nature of science is required to support students in this effort.

\section{Acknowledgements}

The authors would like to thank Professor Merrilyn Goos, Dr Ian Hardy, Dr Jason Tangen, and Peter Ellerton for their feedback, advice and support of various aspects of this research project.

\section{References}

ACARA Australian Curriculum, Assessment and Reporting Authority. (2013). The Australian Curriculum: Science. Retrieved on 1st March 2013 from http://www.australiancurriculum.edu.au/Science/

Berland, L. and Hammer, D. (2012). Framing for scientific argumentation. Journal of Research in Science Teaching, 49(1), 68-94.

Berland, L. and Reiser, B. (2008). Making sense of argumentation and explanation. Science Education, 93, 26-55.

Biggs, J. B., \& Collis, K. F. (1982). Evaluating the quality of learning. New York: Academic Press.

Bloom, B. S. (1956). Taxonomy of Educational Objectives. Vol. 1: Cognitive domain. New York: McKay.

Chin, C., \& Osborne, J. (2010). Supporting argumentation through students' questions: Case studies in science classrooms. The Journal of the Learning Sciences, 19(2), 230-284.

Department for Education and Employment and Qualifications and Curriculum Authority (2004). The National Curriculum for England: Science (Revised).

Driver, R., Newton, P. and Osborne, J. (2000). Establishing the norms of scientific argumentation in classrooms, Science Education, 84(3), 287-312.

Duschl, R. A., Schweingruber, H. A., \& Shouse, A. W. (Eds.). (2007). Taking science to school: Learning and teaching science in grades K-8. National Academies Press.

Erduran, S., Simon, S., \& Osborne, J. (2004). TAPping into argumentation: Developments in the application of Toulmin's argument pattern for studying science discourse. Science Education, 88(6), 915-933.

Jimenez-Aleixandre, M. P., Rodriguez, A. B., \& Duschl, R. A. (2000). “Doing the lesson" or "doing science": Argument in high school genetics. Science Education, 84(6), 757-792.

Kuhn, D. (1992). Thinking as argument. Harvard Educational Review, 62(2), 155-179.

Kuhn, D. (1993). Science as argument: Implications for teaching and learning scientific thinking. Science Education, 77(3), 319_ 337.

Kuhn, D., Black, J., Keselman, A., \& Kaplan, D. (2000). The development of cognitive skills to support inquiry learning. Cognition and Instruction, 18(4), 495-523.

Kuhn, L., \& Reiser, B. (2006). Structuring activities to foster argumentative discourse. In Annual Meeting of the American Educational Research Association, San Francisco, CA.

Kuhn, D. \& Udell, W. (2003). The Development of Argument Skills. Child Development, 74(5), 1245-1260.

Lederman, N. G. (1992). Students' and teachers' conceptions of the nature of science: A review of the research. Journal of Research in Science Teaching, 29(4), 331-359.

McDonald, C. V. (2010). The influence of explicit nature of science and argumentation instruction on preservice primary teachers' views of nature of science. Journal of Research in Science Teaching, 47(9), 1137-1164.

McDonald, C. V., \& McRobbie, C. J. (2012). Utilising argumentation to teach nature of science. In Second International Handbook of Science Education (pp. 969-986). Springer Netherlands.

McNeill, K. L., \& Krajcik, J. (2008). Scientific explanations: Characterizing and evaluating the effects of teachers' instructional practices on student learning. Journal of Research in Science Teaching, 45(1), 53-78.

National Science Teachers Association. (2012). Next generation science standards. Retrieved on 20 February 2014 from http:/ / www.nextgenscience.org/next-generation-science-standards

OECD Programme for International Student Assessment (1999). Measuring student knowledge and skills: A new framework for assessment, Paris: OECD. 
Osborne, Jonathan (2007). Science education for the twenty first century. Eurasia Journal of Mathematics, Science \& Technology Education, 3(3), 173-184.

Osborne, J. (2010). Arguing to learn in science: The role of collaborative, critical discourse. Science, 328(5977), 463-466.

Osborne, J. F., \& Patterson, A. (2011). Scientific argument and explanation: A necessary distinction? Science Education, 95(4), 627638.

Queensland Studies Authority (2007). Queensland Curriculum Assessment Reporting (QCAR) Framework: Science Essential Learnings. Retrieved February, 2014 from http://www.qsa.qld.edu.au/7297.html

Russell, T. L. (1983). Analyzing arguments in science classroom discourse: Can teachers' questions distort scientific authority? Journal of Research in Science Teaching, 20(1), 27-45.

Sampson, V., Grooms, J., \& Walker, J. P. (2011). Argument-Driven Inquiry as a way to help students learn how to participate in scientific argumentation and craft written arguments: An exploratory study. Science Education, 95(2), 217-257.

Sandoval, W. A. (2005). Understanding students' practical epistemologies and their influence on learning through inquiry. Science Education, 89(4), 634-656.

Simon, S. (2008). Using Toulmin's argument pattern in the evaluation of argumentation in school science. International Journal of Research \& Method in Education, 31(3), 277-289.

Simon, S., Erduran, S. and Osborne, J. (2006). Learning to teach argumentation: Research and development in the science classroom. International Journal of Science Education, 28(2), 235-260.

Toulmin, S. (2003). The Uses of Argument. 1958. Cambridge: Cambridge UP.

Tytler, R. (2007). Re-imagining science education: Engaging students in science for Australia's future.

Zohar, A. (2007). Science teacher education and professional development in argumentation. In Argumentation in science education (pp. 245-268). Springer Netherlands. 